\title{
Deaths of children aged under 5 years and related factors in the Islamic Republic of Iran: a population- based case-control study
}

A. Evazpoor ${ }^{7}$, A. Edalati $^{2}$, E. Hyppönen $^{3,4,5}$, M. Fararouei $^{6}$, Z. $^{2}$ Parisai $^{7}$

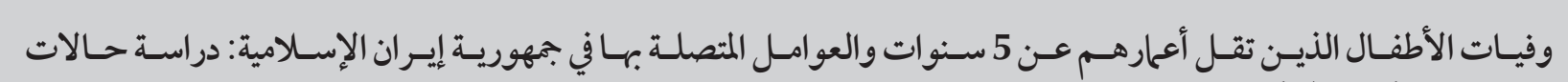

$$
\begin{aligned}
& \text { وشـو اهد سـكانية المرتكـز } \\
& \text { علي رضاعوض بور،، علي عدالاتي، الينا هيبونن، محمد فراروني، ظفر باريساي }
\end{aligned}
$$

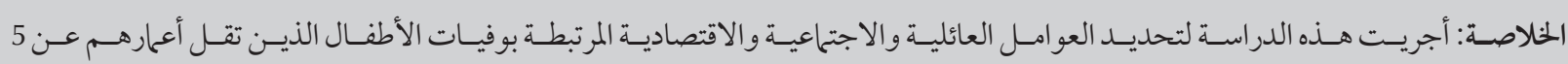

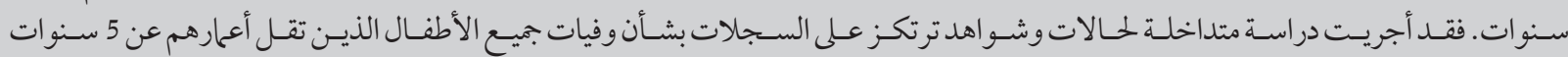

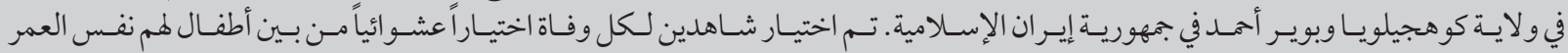

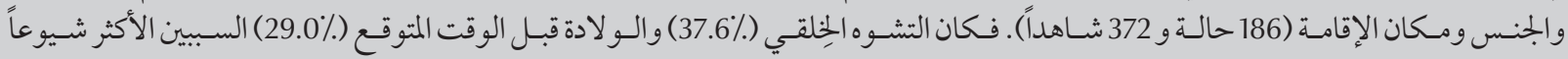

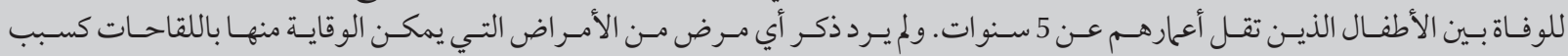

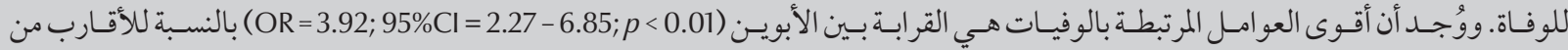

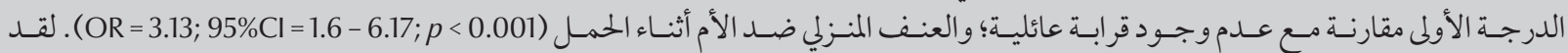

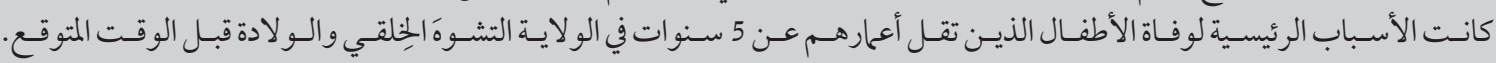

ABSTRACT The study was conducted to determine the family, social and economic factors associated with deaths of children aged under 5 years. A registry-based nested case-control study was conducted of the deaths of all children aged under 5 years in Kohgilooyeh and Boyer-Ahmad Province in the Islamic Republic of Iran. For each death, two controls were randomly selected among children of the same age, sex and place of residence (186 cases and 372 controls). Congenital abnormality (37.6\%) and preterm birth (29.0\%) were the two most frequent causes of death among children aged under 5 years. No vaccine-preventable disease was reported as the cause of death. The strongest associations were found with consanguinity of the parents $(\mathrm{OR}=3.92 ; 95 \% \mathrm{Cl}=2.27-6.85$ for being first cousins in comparison with no family relation; $P<0.001$ ) and with domestic violence to the mother during pregnancy $(\mathrm{OR}=3.13 ; 95 \% \mathrm{Cl}=1.60-6.17 ; P<0.01)$. The main causes of death of children aged under 5 years in the Province were congenital abnormality and prematurity.

Décès d'enfants de moins de cinq ans et facteurs associés en République islamique d'Iran : étude cas-témoin populationnelle

RÉSUMÉ La présente étude a été menée pour déterminer les facteurs familiaux, sociaux et économiques associés aux décès des enfants de moins de cinq ans. Une étude cas-témoin nichée reposant sur les données de registres a été menée sur les décès de tous les enfants de moins de cinq ans dans la province de Kohgilooyeh et Boyer-Ahmad en République islamique d'Iran. Pour chaque décès, deux témoins étaient sélectionnés de façon aléatoire parmi les enfants du même âge, sexe et lieu de résidence (186 cas et 872 témoins). Les malformations congénitales (37,6 \%) et les naissances prématurées (29,0 \%) constituaient les deux causes de décès les plus fréquentes parmi les enfants de moins de cinq ans. Aucune maladie à prévention vaccinale n'a été rapportée comme cause de décès. Les associations les plus fortes étaient liées à la consanguinité des parents $(\mathrm{OR}=3,92$; IC à $95 \%=2,27-6,85$ pour les cousins de premier degré en comparaison avec les sujets n'ayant aucun lien de parenté ; $p<0,001$ ) et à la violence conjugale envers les mères pendant la grossesse $(O R=3,13$; IC à $95 \%=1,60-6,17 ; p<0,01)$. Les principales causes de décès des enfants de moins de cinq ans dans la province étaient les malformations congénitales et la prématurité. 


\section{Introduction}

Childhood mortality has a profound effect on the life expectancy of a community and is considered an important index of a country's health and socioeconomic status (1-3). A primary health care network has been established in the Islamic Republic of Iran over the past three decades to deliver effective health services to the most vulnerable segments of the population, such as mothers and children. Improvements in access to primary health care have resulted in dramatic reductions in maternal and early childhood morbidity and mortality, which are considered the key achievements of the national health care system $(4,5)$. The rate of death of children aged under 5 years (per 1000 live births) was reduced from 287.9 in 1967 to 16.8 in 2013 (6). Safe water, vaccination, safe delivery and other basic health and public services have not only reduced overall mortality rates but have also shifted the causes of morbidity and mortality from infectious to noninfectious diseases.

Thus, the common causes of death among children in the Islamic Republic of Iran have become prematurity, low birth weight and congenital birth defects (4). Many factors contribute to childhood mortality, including the environment, health and social and family factors $(1,7,8)$. The patterns of factors that contribute to the leading causes of death in children must be known to enable targeted planning of programmes for further reductions. We conducted a case-control study, with comprehensive, population-level information collected as part of "family health care file" registrations, complemented by a questionnaire survey. The aim of the study was to determine the causes of death of children aged under 5 years and associated factors in Kohgilooyeh and Boyer-Ahmad Province in southern Islamic Republic of Iran during 1 year.

\section{Methods}

\section{Setting}

Kohgilooyeh and Boyerahmad Province in the southwest of the country has an area of $16249 \mathrm{~km}^{2}$ and a population of 635000 (Fig. 1). The Province has $1.12 \%$ live births, but represents 3.35\% of all deaths of children aged under 5 years in the country (9). Iranian national health legislation requires that all pregnant mothers and children be registered in the national health services network in order to receive basic health care, including vaccination, monitoring of growth and development and nutritional supplements, from birth to 7 years of age. The demographic, social and health information for the families are recorded in a "family health care file".

\section{Selection of deaths}

We selected all deaths of children aged under 5 years in the Province that occurred during an Iranian calendar year equivalent to 20 March 2011 to 19 March 2012. All deaths had been registered in their corresponding health centre, and information on each child had been included in the family health care file prior to their death. The Iranian Ministry of Health and Medical Education requires that a specific procedure be followed for the deaths of all children reported by public health experts or general practitioners, starting with completion of a children's death investigation form. The form is sent to a death investigation expert committee consisting of a paediatrician, an obstetrician and an epidemiologist, which confirms the probable cause of death.

\section{Selection of controls}

Control children were selected from a list of all children who were under 5 years of age, alive on 19 March 2012 and registered in the national health services network. In view of the link to the provision of health care services, the coverage of the register is considered to be virtually complete (10). Two control

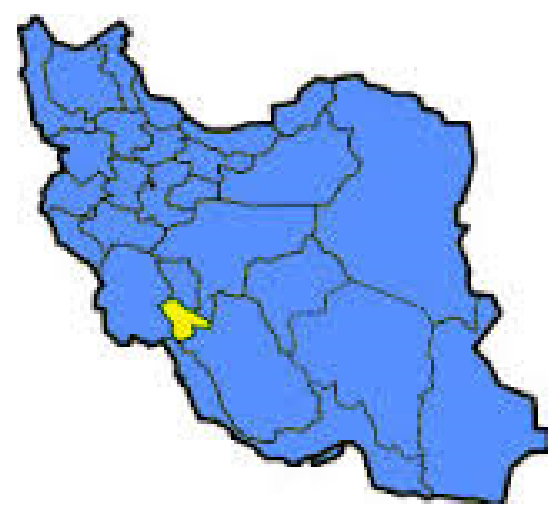

Figure 1. Kohgilooyeh and BoyerAhmad Province (highlighted)

children were randomly selected for each death by frequency matching on age (month), sex and urban or rural residence. Of the 372 mothers who were invited to participate, only four refused (1\%). Replacements were selected for the four refusals by the same criteria as above. We could not use a higher ratio of controls to cases because of the small number of eligible controls in this relatively small population.

\section{Sampling and power}

During the study period, 186 children aged under 5 years died; all were included in the study. To ensure that there were no unreported deaths of children aged under 5 years, we checked all deaths registered at local birth and death offices. An a posteriori power analysis suggested adequate (at least 80\%) statistical power for detecting relevant associations at the $5 \%$ level. For example, the analyses had $90 \%$ power to detect a difference as small as 5\% in the place of birth between the two groups.

\section{Data collection}

Data were collected in 2012 and analysed in 2013. Most information was obtained from the family health care file, including the mother's education and occupation, age at marriage and pregnancy and history of miscarriages and previous pregnancies. Information on the mother's weight gain and regular 
smoking was recorded at each visit to a health centre for routine pregnancy care (on average, 13 visits per pregnancy). The birth characteristics included gestational age (number of weeks from the date of the last normal period) and birth weight. All participants also participated in a structured interview at which information was obtained on social, economic and family factors including consanguinity of the parents, family size, place of residence at birth, mother's education, mother's smoking status, mother's job and satisfaction with the family income and domestic and sexual violence during the pregnancy. All interviews were conducted in a friendly, quiet, private environment by trained female interviewers with a university degree in midwifery or public health. The questionnaire was tested in a pilot study with 53 mothers in Kohgilooyeh and Boyer-Ahmad Province who had children aged under 5 years. As questions about family income were considered to be sensitive and the answers thus potentially unreliable, an indirect question was used, the mothers being asked to report their satisfaction with the family income on a scale of 1-5 (very dissatisfied to very satisfied) $(11,12)$. Violence against mothers was recorded by asking the mothers to report any physical or sexual abuse they had experienced during the pregnancy, after a brief explanation and assurance of confidentiality. The pilot study indicated that the reliability or internal consistency of the questionnaire was good (Cronbach's alpha $=0.7$ ).

The study protocol was approved by the Yasuj University of Medical Sciences ethical committee, and all mothers agreed to participate after reading and signing an informed consent form before the interview; verbal consent was obtained from mothers who were illiterate.

\section{Statistical methods}

Associations between continuous and categorical variables with deaths of children aged under 5 years were tested by Student's t and chi-squared tests, respectively. Multivariate logistic regression was used to analyse the association of each variable with deaths of children aged under 5 years after control for other variables. The final model was built in a backwards selection strategy. Data were analysed with the R statistical package (version 3.0.1).

\section{Results}

In total, 186 deaths of children aged under 5 years occurred during the study period. For each case, two children of the same sex and age were randomly selected from eligible children with the same place of residence (372 controls in total).

Congenital abnormality (37.6\%) and preterm birth (29.0\%) were the most prevalent causes of death (Table
1). None of the deaths was due to a vaccine-preventable disease, and other infectious diseases, including diarrhoea and pneumonia, were responsible for only $12.9 \%$ of all deaths.

The health, family and social characteristics of the cases and controls are presented in Tables 2 and 3. The cases weighed less than controls at birth $(2.42 \mathrm{~kg}$ vs $3.16 \mathrm{~kg}, P<0.001)$ and were born earlier (35.05 vs 38.48 weeks, $P<0.001)$ than the controls. The mothers of the case children were more likely than those of control children to be multiparous ( $15.6 \%$ vs $0.8 \%$, $P<0.001)$ and to have had at least one previous miscarriage ( $17.7 \%$ vs $10.2 \%$, $P=0.015)$. Moreover, the mothers of the case children gained less weight during their pregnancy $(8.37 \mathrm{~kg}$ vs $9.96 \mathrm{~kg}$, $P<0.001)$ and were more likely to have experienced domestic violence than controls ( $18.8 \%$ vs $6.5 \%$, respectively, $P<0.001)$. They had attended fewer visits for maternal care (average, 7.06 vs 8.49 visits, $P<0.001)$. The mothers of the case children were also less satisfied with their family income (55.4\% case mothers and $75.9 \%$ controls were very satisfied or satisfied, $P<0.001)$. In addition, more common between the parents was commoner among the cases than controls: being first cousins was $20.4 \%$ more likely among the parents of the case children than the controls $(P<0.001)$. No significant associations were found between the death of a child aged under 5 years and birth order, birth

\begin{tabular}{|c|c|c|c|c|}
\hline \multirow[t]{2}{*}{ Cause of death } & \multicolumn{3}{|c|}{ Age group } & \multirow[t]{2}{*}{ All } \\
\hline & $<1$ month & 1-12 months & $1-5$ years & \\
\hline Prematurity & $54(50.9 \%)$ & 0 & 0 & $54(29.0 \%)$ \\
\hline Congenital abnormality* & $31(29.2 \%)$ & $24(63.2 \%)$ & $14(34.1 \%)$ & $70(37.6 \%)$ \\
\hline Respiratory illness & $10(9.4 \%)$ & $4(10.5 \%)$ & $1(2.4 \%)$ & $15(8.1 \%)$ \\
\hline Diarrhoea & $2(1.9 \%)$ & $4(10.5 \%)$ & $3(7.3 \%)$ & $9(4.8 \%)$ \\
\hline Domestic or traffic accident & $1(0.9 \%)$ & $4(10.5 \%)$ & $13(31.7 \%)$ & $18(9.7 \%)$ \\
\hline Other & $8(7.5 \%)$ & $2(5.3 \%)$ & $10(24.4 \%)$ & $20(10.8 \%)$ \\
\hline Total & 106 & 38 & 41 & 186 \\
\hline
\end{tabular}

*Age at death was missing for one case 


\begin{tabular}{|c|c|c|c|}
\hline & Cases & Controls & $P$ \\
\hline & No. (\%) & No. (\%) & \\
\hline \multicolumn{4}{|l|}{ Sex } \\
\hline Male & $101(54.3 \%)$ & $202(54.3 \%)$ & \multirow[t]{2}{*}{1.00} \\
\hline Female & $75(45.7 \%)$ & $170(45.7 \%)$ & \\
\hline Birth order & Mean $=2.28, S D=1.54$ & Mean $=2.31, S D=1.40$ & \multirow{4}{*}{0.09} \\
\hline 1 & $83(44.6 \%)$ & $136(36.6 \%)$ & \\
\hline $2-3$ & $66(35.5 \%)$ & $167(44.9 \%)$ & \\
\hline $4-7$ & 37 (19.9\%) & $69(18.5 \%)$ & \\
\hline Birth weight (kg) & Mean $=2.422, \mathrm{SD}=0.940$ & Mean $=3.164, S D=0.538$ & \multirow{5}{*}{$<0.001$} \\
\hline$<2$ & $59(31.7 \%)$ & $7(1.9 \%)$ & \\
\hline $2-2.5$ & $16(8.6 \%)$ & $15(4.0 \%)$ & \\
\hline $2.5-3.5$ & $75(40.3 \%)$ & $236(63.4 \%)$ & \\
\hline $3.5-4.9$ & $21(11.3 \%)$ & $114(30.6 \%)$ & \\
\hline Gestational age (weeks) & Mean $=35.05, \mathrm{SD}=4.88$ & Mean=38.48, SD=1.98 & \multirow{4}{*}{$<0.001$} \\
\hline$<37$ & $82(44.1 \%)$ & $23(6.2 \%)$ & \\
\hline $37-42$ & $101(54.3 \%)$ & $343(92.2 \%)$ & \\
\hline$>42$ & $3(1.6 \%)$ & $6(1.6 \%)$ & \\
\hline \multicolumn{4}{|l|}{ Multiple birth } \\
\hline No & $157(84.4 \%)$ & $369(99.2 \%)$ & \multirow[t]{2}{*}{$<0.001$} \\
\hline Yes & $29(15.6 \%)$ & $3(0.8 \%)$ & \\
\hline
\end{tabular}

interval, family size ( 4.8 for cases vs 4.5 for controls, $P>0.05)$ or mother's education, job or smoking status $(P>0.05)$.

After full adjustment for other variables, the odds for death of children aged under 5 years were increased by low birth weight, consanguinity of parents, history of abortion or domestic violence, smaller family size and residence in rural areas $(P<0.05$ for all comparisons, Table 4). Maternal weight gain and the number of prenatal visits were not associated with deaths of children aged under 5 years, after adjustment. Consanguinity of the parents $(\mathrm{OR}=$ $3.92,95 \% \mathrm{CI}=2.27-6.85$, for children of first-cousin marriages compared with no family relation, $P<0.001$ ) gave the highest odds ratios. The other factor strongly associated with deaths of children aged under 5 years was domestic violence against the mother $(\mathrm{OR}=$ $3.1,95 \% \mathrm{CI}=1.60-6.17, P<0.001)$. When the analyses were restricted to cases who survived at least 12 months $(n=131)$ and their controls, we found a strong protective effect of breastfeeding for at least 6 months (OR $=0.12,95 \%$ $\mathrm{CI}=0.06-0.24, P<0.001)$.

\section{Discussion}

In the Islamic Republic of Iran, as in many other developing countries, a significant reduction in common infectious diseases has made non-infectious disease more common causes of death among children aged under 5 years of age (13). We found that only $12.9 \%$ of the registered deaths of children aged under 5 years in Kohgilooyeh and Boyer-Ahmad Province were due to infectious causes, and, importantly, none of the deaths was due to vaccinepreventable diseases. This national achievement is considered to be (at least partly) the consequence of notable improvements in access to basic health and public services (including mother and child health care, vaccination, safe drinking-water and education) and a significant improvement in public welfare during the past three decades (5).
Our study suggests that the distribution of causes of childhood mortality in our country differs from global patterns, including in particular higher rates of congenital abnormalities and preterm births $(7,13)$ The frequency of congenital abnormalities appears to be even higher in the Province (37\%) than in the country as a whole (17\%) (14).

Our results show that consanguinity of parents is strongly associated with the death of children aged under 5 years, even after adjustment for various other factors. The association was revealed by examining children's death investigation forms, which are available even for rural areas (15). Parental consanguinity is alarmingly common in the Province: $21 \%$ of the parents of cases and $41 \%$ of those of controls were first cousins and $52 \%$ and $72 \%$ were other relatives, respectively. Although we found no official report on national or regional rates of consanguinity, it may explain, at least in part, the high rate of congenital abnormalities in the Province $(16,17)$. We 


\begin{tabular}{|c|c|c|c|}
\hline & Cases & Controls & $\boldsymbol{P}$ \\
\hline & No. (\%) & No. (\%) & \\
\hline Birth interval (years) & Mean=2.28, SD=1.54 & Mean=2.31, SD=1.40 & \\
\hline$\leq 1$ & $15(8.1 \%)$ & $18(4.9 \%)$ & 0.18 \\
\hline $1-2$ & $20(10.8 \%)$ & $40(10.8 \%)$ & \\
\hline $2-3$ & $16(8.6 \%)$ & $51(13.7 \%)$ & \\
\hline$>3$ & $135(72.6 \%)$ & $262(70.6 \%)$ & \\
\hline Family size & Mean $=4.8, \mathrm{SD}=1.87$ & Mean=4.53, SD=1.63 & \\
\hline 3 & $56(30.1 \%)$ & $123(33.1 \%)$ & 0.52 \\
\hline $4-6$ & $16(54.3 \%)$ & $51(54.6 \%)$ & \\
\hline $7-13$ & $135(15.6 \%)$ & $262(12.4 \%)$ & \\
\hline Age of mother at pregnancy (years) & Mean $=27.10, S D=6.02$ & Mean=27.90, SD=5.52 & \\
\hline $15-17$ & $13(7.0 \%)$ & $10(2.7 \%)$ & 0.12 \\
\hline $18-34$ & $156(83.9 \%)$ & $324(87.1 \%)$ & \\
\hline $35-43$ & $17(9.1 \%)$ & $38(10.2 \%)$ & \\
\hline Age of mother at marriage (years) & Mean $=20.09, S D=3.94$ & Mean $=20.81, S D=4.06$ & \\
\hline $12-16$ & $33(17.7 \%)$ & $48(12.9 \%)$ & 0.24 \\
\hline $17-25$ & $135(72.6 \%)$ & $278(74.7 \%)$ & \\
\hline $26-36$ & $18(9.7 \%)$ & $46(12.4 \%)$ & \\
\hline \multicolumn{4}{|l|}{ Previous miscarriage } \\
\hline Yes & $33(17.7 \%)$ & $38(10.2 \%)$ & 0.02 \\
\hline No & $153(82.3 \%)$ & $334(89.8 \%)$ & \\
\hline Weight gained during pregnancy (kg) & Mean $=8.37, \mathrm{SD}=3.68$ & Mean=9.96, SD=3.35 & \\
\hline $1-5$ & $47(25.3 \%)$ & $36(9.7 \%)$ & $<0.001$ \\
\hline $6-10$ & $98(52.7 \%)$ & $193(51.9 \%)$ & \\
\hline 11-15 & $32(17.2 \%)$ & $121(32.5 \%)$ & \\
\hline $16-19$ & $9(4.8 \%)$ & $22(5.9 \%)$ & \\
\hline Number of prenatal care visits & Mean $=7.06, \mathrm{SD}=3.47$ & Mean=8.49, SD=2.97 & \\
\hline $0-4$ & $39(21.0 \%)$ & $31(8.3 \%)$ & $<0.001$ \\
\hline $5-10$ & $118(63.4 \%)$ & $267(73.0 \%)$ & \\
\hline 11-18 & $29(15.6 \%)$ & $73(19.6 \%)$ & \\
\hline \multicolumn{4}{|l|}{ Parents' consanguinity } \\
\hline First cousin & $77(41.4 \%)$ & $78(21.0 \%)$ & $<0.001$ \\
\hline Second cousin and further & $57(30.6 \%)$ & $119(32.0 \%)$ & \\
\hline No family relation & $52(28.0 \%)$ & $175(47.0 \%)$ & \\
\hline \multicolumn{4}{|l|}{ Place of birth } \\
\hline Urban & $44(23.7 \%)$ & $115(30.9 \%)$ & 0.075 \\
\hline Rural & $142(76.3 \%)$ & $257(69.1 \%)$ & \\
\hline \multicolumn{4}{|l|}{ Place of death and interview } \\
\hline Urban & $85(45.7 \%)$ & $172(46.2 \%)$ & 0.93 \\
\hline Rural & $(101(54.3 \%)$ & $200(53.8 \%)$ & \\
\hline \multicolumn{4}{|l|}{ Mother's education } \\
\hline Illiterate & $32(17.2 \%)$ & $55(14.8 \%)$ & 0.22 \\
\hline Primary school & $54(29.0 \%)$ & $108(29.0 \%)$ & \\
\hline Middle school & $38(20.4 \%)$ & $62(16.7 \%)$ & \\
\hline High school & $36(19.4 \%)$ & $104(28.0 \%)$ & \\
\hline Higher & $26(14.0 \%)$ & $43(11.6 \%)$ & \\
\hline \multicolumn{4}{|l|}{ Smoked during pregnancy } \\
\hline Yes & $5(2.7 \%)$ & $10(2.7 \%)$ & 1.00 \\
\hline No & $181(97.3 \%)$ & $362(97.3 \%)$ & 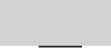 \\
\hline
\end{tabular}




\begin{tabular}{|c|c|c|c|}
\hline & Cases & Controls & $\boldsymbol{P}$ \\
\hline & No. $(\%)$ & No. (\%) & \\
\hline \multicolumn{4}{|l|}{ Mother's occupation } \\
\hline Housewife & $168(90.3 \%)$ & $334(89.8 \%)$ & 0.43 \\
\hline Teacher & $6(3.2 \%)$ & $19(5.1 \%)$ & \\
\hline Employee & $8(4.3 \%)$ & $16(4.3 \%)$ & \\
\hline Self-employed & $4(2.2 \%)$ & $3(0.8 \%)$ & \\
\hline \multicolumn{4}{|l|}{ Income satisfaction } \\
\hline Very satisfied & $19(10.2 \%)$ & $57(15.3 \%)$ & 0.003 \\
\hline Satisfied & $84(45.2 \%)$ & $200(53.8 \%)$ & \\
\hline Neither satisfied nor dissatisfied & $52(28.0 \%)$ & $83(22.3 \%)$ & \\
\hline Dissatisfied & $16(8.6 \%)$ & $23(6.2 \%)$ & \\
\hline Very dissatisfied & $15(8.1 \%)$ & $9(2.4 \%)$ & \\
\hline \multicolumn{4}{|l|}{ Domestic violence during pregnancy } \\
\hline Yes & $35(18.8 \%)$ & $24(6.5 \%)$ & $<0.001$ \\
\hline No & 151 (81.2\%) & $348(93.5 \%)$ & \\
\hline \multicolumn{4}{|l|}{ Sexual abuse during pregnancy } \\
\hline Yes & $18(9.7)$ & $9(2.4 \%)$ & $<0.001$ \\
\hline No & $168(90.3 \%)$ & $363(97.6 \%)$ & \\
\hline
\end{tabular}

also observed an association between domestic violence against the mother

\begin{tabular}{|c|c|c|c|}
\hline & No. & OR $(95 \% \mathrm{Cl})$ & $P$ \\
\hline Preceding birth interval & 558 & $0.95(0.88-1.03)$ & 0.24 \\
\hline Birth weight & 543 & $0.36(0.23-0.56)$ & $<0.001$ \\
\hline Gestational age & 558 & $0.85(0.77-0.94)$ & 0.001 \\
\hline \multicolumn{4}{|l|}{ Place of birth } \\
\hline Urban & 159 & & \\
\hline Rural & 399 & 1.79 (1.030-3.18) & 0.04 \\
\hline Weight gain during pregnancy & 558 & $1.01(0.94-1.08)$ & 0.89 \\
\hline Number of maternity visits & 558 & $0.95(0.88-1.018)$ & 0.15 \\
\hline \multicolumn{4}{|l|}{ History of abortion } \\
\hline No & 487 & & \\
\hline One & 48 & $2.20(1.035-4.64)$ & 0.04 \\
\hline Two and more & 23 & $1.04(0.30-3.21)$ & 0.95 \\
\hline \multicolumn{4}{|l|}{ Consanguinity of parents } \\
\hline No & 155 & & \\
\hline First cousin & 176 & $3.92(2.27-6.85)$ & $<0.001$ \\
\hline Second cousin and further & 227 & $1.62(0.93-2.83)$ & 0.09 \\
\hline Family size & 558 & $1.24(1.09-1.41)$ & 0.001 \\
\hline \multicolumn{4}{|l|}{ Domestic violence } \\
\hline No & 499 & & \\
\hline Yes & 59 & $3.13(1.60-6.17)$ & $<0.001$ \\
\hline
\end{tabular}

Variables in the saturated logistic model: birth interval from previous sibling, birth order, age of mother at pregnancy, age of mother at marriage, single status, prenatal visits, weight gain during pregnancy, birth weight, history of abortion, consanguinity of the parents, family size, place of residency at birth, mother's education, smoking status of the mother, mother's job and family income satisfaction, domestic violence during pregnancy, sexual violence during pregnancy

during pregnancy and an increased risk that her child would die before the age ber intervene when it is observed.

Earlier reports suggested an association between maternal occupation and education with childhood mortality $(8,19)$. In our analyses, the effects of maternal occupation and education did not persist after other contributing factors were accounted for. Also, in contrast to some earlier studies, we found no association between birth interval and death of children aged under 5 years (19), perhaps because there has been a major, nationwide reduction in fertility rate in the country, with a decrease of $59.5 \%$ between the mid1980s and the mid-1990s (20), which is considered to be due to more family planning, increases in the average birth interval and improvements in social and health services (4). For example, in our study, only $6.1 \%$ of the study children had a birth interval from their older siblings shorter than 2 years. This may have attenuated the associations between previously recognized factors (mainly maternal education and birth interval) and deaths of children aged 
under 5 years. We found a strong negative association between breastfeeding and the deaths of children aged under 5 years (21). In our context, this may reflect poorer health and feeding ability among the cases rather than a strong protective effect.

One of the strengths of our study is that it included information on socioeconomic, health and family factors that affect the risk for childhood mortality. We consider that the results can be generalized to many (developing) countries in the Region with similar cultural, social and geographical features. A limitation is that, despite efforts to assure the mothers of the privacy and confidentiality of the information they provided, we cannot exclude possible underreporting of sexual or domestic violence. Furthermore, much of the information was routinely collected data from family health files and death investigation forms. Although health staff try systematically to ensure that the information they collect is valid and reliable, we cannot exclude possible errors in the information from official sources.

Studies based on national or international sources should be conducted to determine the applicability of the results. As the risk factors identified in this study can be modified, populationbased interventions are recommended to apply social and health measures to prevent deaths of children aged under 5 years.

In conclusion, the main causes of deaths of children aged under 5 years in this registry-based, nested case-control study in Kohgilooyeh and Boyer-Ahmad Province in the Islamic Republic of Iran were congenital abnormality and prematurity, while vaccine-preventable causes of death were extremely rare. Consanguinity of parents and domestic violence were important determinants of the deaths of these children, indicating the need for suitable interventions.

\section{Acknowledgements}

We thank the Vice Chancellor for research affairs of Yasuj University of Medical Sciences for financial support. The authors hereby confirm that they have no conflict of interest.

\section{Funding: None.}

Competing interests: None declared.

\section{References}

1. Garenne M. Urbanisation and child health in resource poor settings with special reference to under-five mortality in Africa. Arch Dis Child 2010;95:464-468.

2. Bourne PA, Solan I. Under-five mortality, health and selected macroeconomic variables: the children behind the digits. J Behav Health 2012;3:217-226.

3. Anand S, Bärninghausen T. Human resources and health outcomes: cross-country econometric study. Lancet 2004;364:1603-1609.

4. Lankarani KB, Alavian SM, Peymani P. Health in the Islamic Republic of Iran, challenges and progresses. Med J Islam Republic Iran 2013;27:42

5. Mehrdad R. Health system in Iran. Japan Med Assoc J 2009;52:69-73.

6. Levels and trends in child mortality - Report 2014. In: United Nations Inter-agency Group for Child Mortality Estimation. New York City, New York: UNICEF; 2014.

7. Bryce J, Boschi-Pinto C, Shibuya K, Black RE. WHO estimates of the causes of death in children. Lancet 2005;365:1147-1152.

8. Hosseinpoor AR, Mohammad K, Majdzadeh R, Naghavi M, Abolhassani F, Sousa A, et al. Socioeconomic inequality in infant mortality in Iran and across its provinces. Bull World Health Organ 2005;83:837-844.

9. Official report on Iranian census. Tehran: Statistical Centre of Iran; 2011.

10. Shadpour K. Primary health care networks in the Islamic Republic of Iran. East Mediterr Health J 2000;6:822-825.

11. Senik C. Ambition and jealousy: income interactions in the "old" Europe versus the "new" Europe and the United States. Economica 2008;75:495-513.

12. Kuwert $\mathrm{P}$, Brahler E, Glaesmer H, Freyberger $\mathrm{H}$ Jr, Decker O. Impact of forced displacement during World War II on the present-day mental health of the elderly: a population-based study. Int Psychogeriatr 2009;21:748-753.
13. Black RE, Cousens S, Johnson HL, Lawn JE, Rudan I, Bassani DG, et al. Global, regional, and national causes of child mortality in 2008: a systematic analysis. Lancet 2010;375:1969-1987.

14. Movahedi M, Hajarizadeh B, Rahimi A, Arshinchi M, Amirhosseini K, Haghdoost AA. Trends and geographical inequalities of the main health indicators for rural Iran. Health Policy Plan 2009;24:229-237.

15. Chaman R, Gholami Taramsari M, Khosravi A, Amiri M, Holakouie Naieni K, Yunesian M. Consanguinity and neonatal death: a nested case-control study. J Fam Reprod Health 2014;8:189-193.

16. Bromiker R, Glam-Baruch M, Gofin R, Hammerman C, Amitai Y. Association of parental consanguinity with congenital malformations among Arab newborns in Jerusalem. Clin Genet 2004;66:63-66.

17. Nabulsi MM, Tamim H, Sabbagh M, Obeid MY, Yunis KA, Bitar FF. Parental consanguinity and congenital heart malformations in a developing country. Am J Med Genet A 2003;116A:342347.

18. Åsling-Monemi K, Tabassum Naved R, Persson LA.. Violence against women and the risk of under-five mortality: analysis of community-based data from rural Bangladesh. Acta Paediatr 2008;97:226-232.

19. Dwivedi SN, Pandey RM. Determinants of under-five mortality in Rural Empowered Action Group states in India: an application of Cox frailty model. Int J Matern Child Health AIDS 2012;1:60-72.

20. Abbasi-Shavazi MJ. Effects of marital fertility and nuptiality on fertility transition in the Islamic Republic of Iran, 1976-1996. Canberra: The Australian National University; 2000.

21. Lamberti LM, Zakarija-Grkovic I, Walker CLF, Theodoratou E, Nair H, Campbell H, et al. Breastfeeding for reducing the risk of pneumonia morbidity and mortality in children under two: a systematic literature review and meta-analysis. BMC Public Health 2013;13(Suppl 3):S18. 